\title{
CURRÍCULO, EDUCAÇÃO FÍSICA E MARABAIXO: FUNDAMENTAN- DO CAMINHOS PARA INSERÇÃO DA CULTURA AFRO-BRASILEIRA NA ESCOLA DO AMAPÁ 1
}

\author{
Bruna Cardoso Gonçalves \\ Universidade Federal do Amapá, Macapá, Amapá, Brasil. \\ Paulo Magalhães Monard Nascimento \\ Governo do Estado do Amapá, Macapá, Amapá, Brasil. \\ Alvaro Adolfo Duarte Alberto \\ Universidade Federal do Amapá, Macapá, Amapá, Brasil.
}

\begin{abstract}
Resumo
O Marabaixo é uma manifestação cultural afro-brasileira do Estado do Amapá que representa um movimento de resistência/luta contra a opressão da população negra. O presente artigo objetivou analisar caminhos para superação da ausência/secundarização do Marabaixo nas aulas de Educação Física no Amapá, tendo como referência os estudos curriculares e as identidades da Educação Física brasileira. Identificamos que o desafio de incluir o Marabaixo como conteúdo de ensino da Educação Física nas escolas do Amapá pode ser enfrentado pela perspectiva que reconhece que os objetivos deste componente curricular estão centrados nos sentidos e significados das manifestações corporais enquanto patrimônio cultural da humanidade.
\end{abstract}

Palavras-chave: Marabaixo. Educação Física. Currículo.

\section{CURRICULUM, PHYSICAL EDUCATION AND MARABAIXO: FOUNDING PATHS FOR INSERTION OF AFRO-BRAZILIAN CULTURE IN AMAPÁ SCHOOL}

\begin{abstract}
The Marabaixo is an Afro-Brazilian cultural manifestation of the State of Amapá, which represents a movement of resistance/struggle against the oppression of the black population. The present article aimed to analyze ways to overcome the absence/ secondaryization of Marabaixo in Physical Education classes in Amapá, taking as reference the curricular studies and the identities of brazilian Physical Education. We have identified that the challenge of including Marabaixo as content of Physical Education teaching in the schools of Amapá can be confronted by the perspective that recognizes that the objectives of this curricular component are centered in the meanings and meanings of the manifestations of the body as the cultural patrimony of humanity.
\end{abstract}

Keywords: Marabaixo. Physical Education. Curriculum.

\footnotetext{
${ }^{1} \mathrm{O}$ presente trabalho não contou com apoio financeiro de nenhuma natureza para sua realização.
} 


\title{
CURRICULUM, EDUCACIÓN FÍSICA Y MARABAIXO: FUNDAMENTANDO CA- MINOS PARA INSERCIÓN DE LA CULTURA AFRO-BRASILEÑA EN LA ESCUE- LA DE AMAPÁ
}

\begin{abstract}
Resumen
El Marabaixo es una manifestación cultural Afro-Brasileña del Estado de Amapá, que representa un movimiento de resistencia/lucha contra la opresión de la población negra. El presente artículo objetivó analizar caminos para superar la ausencia/secundarización del Marabaixo en las clases de Educación Física en Amapá, teniendo como referencia los estudios curriculares y las identidades de la Educación Física brasileña. Identificamos que el desafío de incluir el Marabaixo como contenido de enseñanza de la Educación Física en las escuelas de Amapá, puede ser enfrentado por la perspectiva que reconoce que los objetivos de este componente curricular están centrados en los sentidos y significados de las manifestaciones corporales, como patrimonio cultural de la humanidad.
\end{abstract}

Palabras clave: Marabaixo. Educación Física. Curriculum.

\section{Introdução}

Durante muito tempo, as produções relacionadas às populações negras - saberes, conhecimentos, expressões artísticas - ficaram ausentes ou secundarizadas no itinerário da Educação Básica. Embora tenha determinante presença na construção histórica, social, política, econômica e cultural do Brasil, no geral, as referências à cultura afro-brasileira são pautadas no currículo escolar regular de forma limitada e descontextualizada da realidade de opressão e exclusão pela qual passaram e ainda passam as populações negras no nosso país.

No caso do componente curricular Educação Física, esta realidade de negligência se mantém. O currículo dessa disciplina tem como referência hegemônica as práticas corporais europeias e estadunidenses e por um longo período apresentou um distanciamento das principais questões didático-pedagógicas que subsidiam o ensino escolar. As práticas pedagógicas da Educação Física giraram, essencialmente, em torno das perspectivas da aptidão física e do esporte e, apenas nos últimos anos com o chamado movimento renovador da Educação Física, incorporaram uma discussão mais crítica acerca das práticas corporais enquanto construção social e manifestação cultural de um povo.

É a partir desse contexto que se legitima a inserção de danças de matriz africana, como o Marabaixo, na condição de conteúdo de ensino da Educação Física escolar. O Marabaixo é uma manifestação cultural afro-brasileira do Estado do Amapá que representa um movimento de resistência/luta contra a opressão da população negra na comunidade amapaense e tem a dança como uma de suas expressões mais simbólicas. Apesar da forte presença na cultura popular amapaense, essa manifestação cultural não vem sendo reconhecida enquanto conteúdo de ensino de forma sistematizada, contextualizada e crítica nas aulas de Educação Física.

Nesse sentido, é fundamental compreender as questões curriculares e as identidades da Educação Física brasileira para superar um contexto que negligencia a cultura afro-brasileira nos textos da escola amapaense. A partir desse cenário, o presente artigo objetivou analisar caminhos para superação da ausência/secundarização do Marabaixo nas aulas de Educação Física no Amapá, tendo como referência os estudos curriculares e as identidades da Educação Física brasileira. Trata-se de um estudo de caráter conceitual, baseado numa pesquisa bibliográfica, que estabelece uma aproximação sistematizada à obra de um grupo específico de autores e autoras que debatem, de um lado, as questões curriculares da Educação Física numa perspectiva pós-crítica e, de outro, o contexto do Marabaixo na educação formal. 


\section{Currículos e Teorias Curriculares}

O currículo, ao longo da história da educação, foi percebido ou mesmo concebido de formas diferentes. Isto é, em função das diversas concepções de ser humano, de sociedade e de escola, surgiram também várias concepções de currículo. Pensar, portanto, em uma definição única e fechada de currículo talvez seja uma questão problemática, uma vez que uma definição por si só, na realidade, não seria capaz de capturar o que é, em essência, o currículo, mas apenas um entendimento acerca do mesmo.

Silva (2011) apresenta uma abordagem de referência sobre os estudos curriculares, ilustrando uma classificação para as teorias predominantes na história da educação, a saber: teorias tradicionais, teorias críticas e teorias pós-críticas.

As teorias curriculares tradicionais são caracterizadas pela tendência mecânica/técnica, de valorização do rigor organizacional e de busca de eficiência dos resultados nos processos educacionais. Trata-se do entendimento de que os objetivos da educação já estão dados pelas demandas da vida profissional adulta e, portanto, a problemática do currículo limita-se a uma questão unicamente técnica, de definição de padrões, metas, hierarquização das experiências educacionais e sistematização dos mecanismos de controle da aprendizagem.

Já as teorias curriculares críticas, fundamentadas em discussões amplas acerca da lógica da sociedade e da escola, sustentam um olhar de problematização e transformação social. A partir da perspectiva crítica, legitima-se a noção de que o currículo é uma construção social e, portanto, não é neutro, mas carrega intencionalidades. Nesse sentido, as teorias críticas sustentam que o currículo funciona como um aparelho ideológico do capitalismo ao transmitir crenças, valores, princípios, modo de vida e os saberes do grupo social economicamente dominante, criando mecanismos para reprodução da estrutura básica da sociedade capitalista (SILVA, 2011).

As teorias pós-críticas, para além da dinâmica de classes, sustentam que as questões curriculares envolvem outras relações de poder, em especial, sobre microcontextos e destacam discursos sobre identidades e diferenças. As teorias pós-críticas ensinam que o centro das relações de poder está distribuído entre segmentos sociais e culturais distintos e salientam, principalmente, os contextos de subordinação envolvendo etnia, raça, gênero e sexualidade.

No geral, as referências a grupos sociais e culturais subjugados historicamente, como as populações negras, são pautadas no currículo escolar enquanto elementos folclóricos, com caráter mítico e, por conseguinte, com menor valor no contexto educativo. Um currículo póscrítico questiona o racismo e celebra a diferença a partir de uma perspectiva que desconfia das construções históricas, institucionais e discursivas que legitimaram atitudes individuais e coletivas de preconceito. Nessa direção, pensar a ampliação da representação das identidades excluídas do currículo tradicional torna-se matéria central na perspectiva pós-crítica (SILVA, 2011).

Pela perspectiva pós-crítica, o currículo é um instrumento de inserção, legitimação e valorização de produções culturais de grupos subordinados, que normalmente são secundarizados no ambiente escolar, criando enfrentamento a situações de silenciamento e preconceito (NEIRA, 2009).

\section{Currículos e Identidades da Educação Física brasileira}

A Educação Física foi inserida no sistema escolar brasileiro em meados do século XIX, sob forte influência das instituições militares e médicas. Inicialmente denominada de ginástica, a Educação Física desenvolveu um currículo de perspectiva higienista, de objetivos profiláticos e corretivos, através da difusão de condutas de higiene, de saúde e de disciplina, nas dimensões: física e moral. De acordo com Ilha e Ivo (2011), para essa perspectiva de E- 
ducação Física, o homem era concebido como ser biológico e a prática pedagógica tinha como referência os saberes anátomo-fisiológicos do corpo e possuía o exercício físico como objeto principal. Já para Bracht (1999), a abordagem pedagógica dessa Educação Física, considerada na época uma disciplina escolar essencialmente prática, acumulava a função de construir corpos saudáveis e dóceis adaptados ao processo produtivo e, ao mesmo tempo, legitimava uma visão médico-científica sobre o corpo.

No período pós-guerra, o contexto educacional foi invadido pela influência desenvolvimentista que se alinha com argumentos de eficiência e eficácia, afinados com as novas características do mundo do trabalho. Em correspondência a esse contexto, no currículo da Educação Física emerge outra característica: a centralidade do esporte como conteúdo de ensino. No entendimento de Bracht (1999), a prática esportiva foi assimilada sem grandes dificuldades pela Educação Física na escola, uma vez que o núcleo de fundamentação do conhecimento se manteve praticamente o mesmo: o foco no funcionamento orgânico do corpo, através das ciências biológicas e médicas, aplicadas ao contexto do desempenho esportivo.

Esse modelo curricular se consolidou especialmente no cenário da ditadura civilmilitar brasileira, através da referência tecnicista que aproximou a Educação Física da experiência prática do treinamento esportivo. Nunes e Rúbio (2008) reconhecem que esse currículo, denominado de técnico e esportivizado, promoveu a formação de alunos e alunas adequados aos sistemas simbólicos hegemônicos, afastando e desqualificando perfis discrepantes.

González e Fensterseifer (2009) argumentam que a consolidação do currículo técnicoesportivo representou um movimento de grande repercussão que, na realidade prática da escola, instituiu uma relação de quase simbiose entre Educação Física e esporte. Ainda para esses autores, a chamada esportivização da Educação Física foi o fenômeno que promoveu a prática esportiva como conteúdo hegemônico da Educação Física, a tal ponto de "no senso comum, ser plenamente possível confundir Educação Física escolar com prática esportiva" (GONZÁLEZ; FENSTERSEIFER, 2009, p. 10).

O discurso curricular de aptidão física e esportiva só foi questionado de maneira mais expressiva a partir do início do período de redemocratização do Brasil, na década de 1980. Para Nunes e Rúbio (2008), esse momento é caracterizado como de crise de identidade da Educação Física escolar, uma vez que diversas críticas foram levantadas ao modelo curricular em vigor, bem como foram elaboradas diferentes abordagens que focavam na construção de outro referencial teórico-conceitual para o campo da Educação Física.

Para González e Fensterseifer (2009), o movimento de crítica aos paradigmas de aptidão física e esportiva do currículo, denominado movimento renovador da Educação Física brasileira, foi responsável por impulsionar um processo importante de mudanças na área. Pois, além de propor a superação do discurso curricular hegemônico, buscou tirar a Educação Física da condição de mera atividade e elevá-la ao patamar de componente curricular obrigatório na formação escolar básica.

Inicialmente, surgiram correntes teóricas fundamentadas na psicologia da aprendizagem que tinham por finalidade promover o desenvolvimento da criança nas dimensões motoras, afetiva e cognitiva, além de difundir padrões de movimento rigorosamente hierarquizados. Na realidade, as correntes conhecidas como desenvolvimentista (TANI et al., 1988) e psicomotora (FREIRE, 1989), apesar de levantarem críticas ao currículo tradicional da Educação Física, pouco dialogaram com uma concepção curricular de natureza crítica. Na prática, ainda persistiam as referências fundamentais do propósito curricular de matriz tradicional.

Somente no início da década de 1990 surgem propostas curriculares que vinculam a Educação Física às temáticas da pedagogia crítica e, portanto, pontuam alternativas ao currículo dominante. Em termos gerais, as abordagens conhecidas como progressistas da Educação Física defendem que as formas de sistematizar o movimento do corpo pelo pensamento he- 
gemônico, as correntes da aptidão física e da esportivização, representavam maneiras de reproduzir valores e signos dos grupos sociais dominantes.

Para Bracht (1999), as correntes curriculares progressistas da Educação Física se interessam por sistematizar na escola o corpo em movimento como forma de expressão da cultura, como patrimônio cultural da humanidade, a partir de uma abordagem didático-pedagógica. Nesse caso, a Educação Física elege como seu objeto de estudo a cultura corporal que na prática compreende as manifestações corporais construídas pela humanidade e são dotadas de dimensões históricas, sociais, antropológicas, culturais, tais como: o jogo, a ginástica, a dança, a luta e o esporte. Esse pensamento crítico na Educação Física foi balizado nas abordagens crítico-superadora (SOARES, et al., 1992) e crítico-emancipatória (KUNZ, 1994).

Mais recentemente foram difundidas algumas ideias sobre um currículo de Educação Física orientado pela perspectiva pós-crítica. Nunes e Neira (2009) argumentam que o currículo tradicional da Educação Física tem como influência hegemônica as práticas corporais europeias e estadunidenses que vêm sendo consideradas como referência universal para as aulas. Em contraponto a essa ideia, o currículo de Educação Física de orientação pós-crítica propõe a tematização e a problematização de práticas corporais vinculadas a grupos minoritários, dominados e subalternos. Na prática pedagógica, essa abordagem visaria ao "reconhecimento dos aspectos identitários do grupo/região/manifestação investigado(s) e radicalizaria a crítica social e cultural desses artefatos com base na perspectiva dos Estudos Culturais" (NUNES; NEIRA, 2009, p. 237).

Essa proposta, que almeja uma atividade pedagógica comprometida com a diversidade e com o reconhecimento de construções sociais e cultural de grupos marginalizados, está diretamente alinhada com a inserção da cultura afro-brasileira nas aulas de Educação Física. Pautar nas aulas as danças populares de matriz africana que se desenvolveram no Brasil representa uma oportunidade de valorizar a cultura negra brasileira, respeitando a pluralidade e criando mecanismo para que as crianças e jovens estabeleçam relação e integração nas diferenças.

\section{Marabaixo: história e resistência da população negra no Amapá}

O Marabaixo compreende uma festividade que acontece na cidade de Macapá, capital do Estado do Amapá, situado na região Norte do Brasil. Para Videira (2014), a realização do Marabaixo é fruto de uma rica composição que inclui, além da dança, o festejo, a bebida, a fé, as folias e as ladainhas, as missas, os fogos, os cortejos, as dramatizações e as promessas. Além disso, é uma manifestação cultural que reúne diversas gerações durante o chamado Ciclo do Marabaixo, que se configura como o período do ano destinado aos festejos dessa tradição. Na prática, trata-se da maior manifestação cultural afro-amapaense, considerada como patrimônio histórico e cultural do Estado do Amapá.

A chegada de populações negras em solo amapaense data, oficialmente, do período de 1751 e 1765. Esse movimento envolvendo povos negros africanos ocorreu através do processo de colonização das terras amapaenses, com a chegada de muitas famílias de colonos de várias partes do Brasil para povoar Macapá (MORAIS, 2009). Através dessas famílias, muitos negros chegaram ao Estado na condição de escravos, porém, o maior contingente chegou ao Amapá para a construção da Fortaleza de São José de Macapá, que teve sua obra iniciada em 1764 e concluída em 1782.

A origem do Marabaixo está atrelada ao período em que ocorreram as modernizações das cidades em todo o país, a partir do ano de 1930 (PESSOA; VERENA, 2015). No Amapá, esse processo de modernização resultou na expulsão da população negra de origem africana que habitava o centro da cidade para os bairros periféricos como, por exemplo, os bairros Laguinho e Favela. Esse movimento objetivou ceder espaço em torno de locais considerados 
nobres da cidade, como a Igreja e a Fortaleza de São José de Macapá, para a construção de áreas que serviriam para classe dominante e mais abastada.

Custódio (2016) descreve que entre as décadas de 1930 e 1940 ocorreu essa reorganização da cidade de Macapá, gerando diversas transformações nos âmbitos: social, político, econômico, cultural, para consolidar um projeto de povoar, sanear e educar a cidade, que teve como principal impacto a transferência, segregação e exclusão da população negra do centro da cidade. Custódio (2016, p. 70) considera que nesse período ocorreu o "primeiro saneamento étnico do centro da cidade, quando negros e negras tiveram que deixar suas casas para que fosse viabilizada a construção de conjuntos residenciais para assessores do governo territorial e outros funcionários."

A partir desse contexto, as danças e as cantigas do Marabaixo, os chamados ladrões, tornaram-se instrumentos de denúncia e contestação política e serviram para revelar a história das populações afrodescendentes, o tratamento que era dispensado aos negros, assim como o espaço designado aos mesmos dentro da cidade. Neste trecho de um ladrão de Marabaixo, é possível observar esta denúncia: - Aonde tu vai rapaz/Por esses caminhos sozinho?/ - Eu vou fazer minha morada/Lá nos campos do Laguinho.

Nos dias de hoje, nota-se que os bairros Laguinho e Favela ainda são formados por maioria de afrodescendentes, já que esses foram os locais destinados à segregação dos escravos que viviam em Macapá. Esses também são os bairros que festejam, divulgam, vivenciam e que preservam, nos dias atuais, a tradição cultural herdada dos escravos advindos da África, por isso são bairros reconhecidos como de negros.

Atualmente, em todos os anos, o Marabaixo é festejado no Ciclo do Marabaixo, destinado para dança, festejo, reza, encontro e comemoração de duas referências católicas, o Divino Espírito Santo e a Santíssima Trindade. Custódio (2016) salienta que essa festa está dividida em dois momentos: o religioso, iniciado pelas ladainhas, rezas, missas, oferendas e promessas; e o festivo, regado à dança, com o acompanhamento dos ladrões e do som das caixas de Marabaixo, que são os instrumentos percussivos utilizados para ritmar o festejo.

Videira (2014) descreve que a dança do Marabaixo é embalada e ritmada pelas caixas de Marabaixo e pelos ladrões. De acordo com essa autora, trata-se de uma dança coletiva, executada em roda que gira no sentido anti-horário e que tem como passo básico o movimento dos pés arrastados, um seguindo o outro no chão, que são acompanhados em sintonia pelo molejo dos quadris. Os pés arrastados caracterizam a forma como os escravos dançavam com os tornozelos presos por grilhões, espécie de corrente metálica, que não permitiam maiores amplitudes de movimento (PESSOA; VENERA, 2015).

Ainda pela descrição de Videira (2014), as dançadeiras de Marabaixo utilizam um traje específico composto de anágua, saia estampada, arranjos de flores na cabeça, blusa com folho, toalhas sobre os ombros e acessórios como colares, argolas e pulseiras. As mulheres, como utilizam saias rodadas e longas, fazem uso do traje para completar a dança, segurando a ponta da saia no bailado do Marabaixo. Os homens na dança têm o papel de cortejar a mulher. De forma geral, a dança do Marabaixo não segue um padrão coreográfico, pois os movimentos são executados livremente, sempre com um toque de alegria, malícia, cheia de graça e ginga em harmonia com o canto, os instrumentos de percussão e a dança. Não existe, portanto, hierarquias no espaço cênico, o que permite que as pessoas envolvidas possam expressar suas emoções e sentimentos durante a execução da dança.

Em aspectos gerais, pode-se afirmar que o Marabaixo é uma tradição advinda das populações negras que viveram no Amapá na condição de escravos e representa uma expressão de luta e resistência contra as formas de opressão. Como dança popular, possui uma relevante dimensão social, cultural e política que liga a população negra à história do povo amapaense. Para Pessoa e Venera (2015), o Marabaixo é um movimento político de resistência que busca, através dos seus cantos e sua dança, denunciar práticas excludentes no Estado do Amapá. Tra- 
ta-se, portanto, de uma manifestação importante de enfrentamento à opressão e que, nos dias de hoje, almeja garantir que a cultura afrodescendente seja valorizada e reconhecida como fenômeno crucial para a construção do Estado do Amapá e da cidade de Macapá.

\section{Marabaixo: conteúdo de ensino escolar}

É possível reconhecer que a inserção do Marabaixo como conteúdo de ensino nas escolas do Amapá pode contribuir para divulgar e legitimar parte da história do povo amapaense, fazendo com que essa expressiva manifestação cultural da população negra seja conhecida, reconhecida, respeitada e valorizada. Além disso, trabalhar pedagogicamente o Marabaixo na escolar pode representar visibilidade à luta, à superação de estereótipos e preconceitos relacionados às populações negras no Brasil.

Dessa maneira, entendemos que problematizar de forma crítica as práticas culturais afrodescendentes, como por exemplo, o Marabaixo, dentro do espaço escolar significa dar vez e voz à cultura tradicional afrodescendente que é negligenciada e quase inexistente no currículo oficial escolar. Nesse sentido, é válido perceber que o trabalho pedagógico consistente e criticamente situado, envolvendo questões étnicas raciais, configura-se como uma maneira de superar preconceitos e discriminações.

É importante ainda destacar que a educação escolarizada pode ser um instrumento de manutenção dos elementos hegemônicos da sociedade, bem como, pode instaurar um espaço/tempo para questionar a cultura dominante, apontando para transformação social (NUNES; NEIRA, 2009). Entretanto, acrescentar temáticas que não sejam integrantes da cultura hegemônica não é suficiente para questionar a ordem majoritária. Para superar as abordagens que atribuem caráter folclórico e exótico às práticas culturais das populações negras, como o Marabaixo, consideramos interessante elaborar uma prática pedagógica problematizadora que levante críticas à maneira como parte da sociedade enxerga as manifestações culturais de populações marginalizadas, como as comunidades negras no Amapá, e valorize suas perspectivas.

Para Moreira e Candau (2003, p. 167) é relevante "questionar os lugares comuns, as leituras hegemônicas da nossa cultura e de suas características, assim como das relações entre os diferentes grupos sociais e étnicos". Além disso, esses autores pontuam a necessidade de proporcionar na escola um trabalho que promova a interação das crianças e jovens com diferentes grupos culturais e étnicos, visando à construção de uma perspectiva sensível com relação à cultura do outro.

\section{Marabaixo: conteúdo de ensino da Educação Física}

$\mathrm{Na}$ análise desenvolvida no presente artigo, acredita-se que pensar o Marabaixo numa abordagem pedagógica ampliada na Educação Física escolar demanda reconhecer a teoria pós-crítica como possibilidade para o fazer didático. Na leitura pós-crítica, a Educação Física concentra sua atenção sobre a gestualidade, seus significados, seus ritos, seus adereços e sua dinâmica organizacional, garantindo visibilidade para o patrimônio cultural corporal de grupos marginalizados. Nesse sentido, o que se objetiva é "o desenvolvimento de uma ação pedagógica sensível às diferenças e comprometida com a formação de identidades democráticas" (ETO; NEIRA, 2017, p. 585).

Para Bonetto e Neira (2017), isso pode significar a inserção no repertório escolar de práticas corporais e as biografias, as histórias de dominação e resistência relacionadas a elas, problematizando ainda representações e discursos discriminatórios e preconceituosos. Com isso, não se busca a exclusão da cultura corporal dominante. Na realidade, "defende-se simplesmente que os conhecimentos alusivos às práticas corporais desdenhadas ou tergiversadas 
possam receber a mesma atenção que as manifestações hegemônicas" (BONETTO; NEIRA, 2017, p. 80).

No caso do Marabaixo, a escassez de pesquisas que sistematizem esta manifestação cultural como prática pedagógica da Educação Física conduz para necessidade de produzir análises a partir de outras experiências de ensino. Como, por exemplo, as apresentadas por Eto e Neira (2017) que fizeram um levantamento de alguns relatos de experiências pedagógicas, com o componente curricular Educação Física, orientados pelas correntes pós-críticas.

No caso dessas experiências pedagógicas, foram tematizados a capoeira, o futebol e as questões de gênero e o samba. No geral, essas experiências foram motivadas mediante o diagnóstico do professor acerca de situações que aconteciam entre os estudantes de discriminação e preconceito em relação às práticas culturais de populações afro-brasileiras e às questões de gênero. Além disso, as motivações para a abordagem sobre esses temas estiveram relacionadas à constatação acerca da ausência desses tópicos do currículo clássico da Educação Física, muito focado na tradição de práticas corporais europeias (ETO; NEIRA, 2017).

Os objetivos pedagógicos dessas experiências estavam voltados a aproximar os alunos das práticas corporais relacionadas aos grupos minoritários, questionar preconceitos e promover a igualdade entre grupos sociais e culturais. As atividades didático-pedagógicas, para além do ensino de técnicas de elementos motores, basearam-se em visitas a espaços de referência, pesquisas, atividades extraclasses, recepção de grupos e pessoas com contato íntimo com as práticas corporais tematizadas, rodas de conversas, além da produção pelos alunos de painéis de exposições (ETO; NEIRA, 2017).

Na percepção de Eto e Neira (2017), essas experiências de ensino focaram sua preocupação em contextos locais, nos quais foi possível diagnosticar questões de identidade e diferença. A ação pedagógica estava inclinada a alcançar mudanças nas esferas das subjetividades, visando a desestabilizar discursos hegemônicos. Os autores consideram que o trabalho da Educação Física, apoiado nas teorias pós-críticas, tem preocupação com produção identitária de grupos culturais, centrado na "luta pelo direito de os grupos sociais marginalizados terem representado seu patrimônio cultural corporal no currículo escolar" (ETO; NEIRA, 2017, p. 588).

\section{Algumas considerações}

Reconhecemos que um dos caminhos para uma ação pedagógica democrática e socialmente justa na Educação Física escolar tem como referências principais os fundamentos e objetivos das teorias curriculares pós-críticas. Nesse sentido, entendemos ainda que a inserção do Marabaixo como conteúdo de ensino da Educação Física, direcionado à superação de abordagens que o elegem como cultura exótica e folclórica, também tem sustentação nas perspectivas pós-críticas.

Vale salientar que durante muito tempo o currículo da Educação Física esteve muito atrelado a práticas corporais originárias da Europa e dos Estados Unidos e orientado pelo paradigma da aptidão física e do desporto. Ou seja, a tradição do campo da Educação Física legitima um currículo referenciado pela mecânica do movimento corporal e que pouco dialoga com as produções culturais corporais nacionais, perpetuando um processo de silenciamento, especialmente, no que diz respeito a expressões corporais vinculadas a populações negras no Brasil.

Nessa direção, identificamos que o desafio de incluir o Marabaixo como conteúdo de ensino da Educação Física nas escolas do Amapá pode ser enfrentado pela perspectiva que reconhece que os objetivos desse componente curricular estão centrados nos sentidos e significados das manifestações corporais enquanto patrimônio cultural da humanidade. Além do 
mais, torna-se fundamental eleger a democratização de práticas corporais de grupos marginalizados como meta do processo educacional.

Ademais, o desafio consiste em sistematizar uma abordagem pedagógica que dê conta de tematizar o Marabaixo nas escolas do Amapá visando a incluir, para além da experiência corporal com a dança do Marabaixo, a desmistificação de estereótipos, o desvelar de preconceitos e processos de discriminação envolvendo essa manifestação cultural. Nesse caso, o debate em torno do racismo e demais situações discriminatórias envolvendo pessoas negras no Amapá e no Brasil, a partir das práticas corporais, torna-se necessário.

Nesse propósito, várias metodologias podem ser empregadas. Além de explorar a dimensão da experimentação da vivência corporal com a dança do Marabaixo, é possível aproximar as crianças e jovens dos locais onde acontece o Ciclo do Marabaixo, permitir que alunos dialoguem com as pessoas que promovem o festejo, conheçam a história de luta e opressão da população negra no Amapá e, principalmente, identifiquem e discutam sobre as situações de preconceito e racismo que são denunciadas nessa manifestação cultural. Estas propostas metodológicas possibilitam explorar outras dimensões do conhecimento sobre a dança do Marabaixo, através da compreensão e da construção de outros valores.

\section{Referências}

BONETTO, P. X. R.; NEIRA, M. G. Multiculturalismo: polissemia e perspectivas na Educação e Educação Física. Dialogia, São Paulo, n. 25, p. 69-82, 2017.

BRACHT, V. A constituição das teorias pedagógicas da educação física. Cadernos CEDES, V. 19, n. $48,1999$.

CUSTÓDIO, Elivaldo Serrão. A presença negra no Amapá: discursos, tensões e racismo. Identidade! São Leopoldo, v. 21 n. 1, p. 65-79, 2016.

ETO, J.; NEIRA, M. G. Em defesa de uma teoria pós-crítica de Educação Física. Pensar a Prática, Goiânia, v. 20, n. 3, 2017.

FREIRE, J. B. Educação de corpo inteiro: teoria e prática da educação física. São Paulo: Scipione, 1989.

GONZÁLEZ, F. J.; FENSTERSEIFER, P. E. Entre o "não mais" e o "ainda não": pensando saídas do não-lugar da EF escolar I. Cadernos de Formação RBCE, v. 1, n. 1, p. 9-24, 2009.

ILHA, F. R. S.; IVO, A. A. As Teorias Curriculares da Educação e o currículo da Educação Física. Atividade Física, Lazer \& Qualidade de Vida: Revista de Educação Física, Manaus, v. 2, n. 2, p. 21-33, 2011.

KUNZ, E. Transformação didático-pedagógica do esporte. Ijuí: Unijuí, 1994.

MORAIS, Paulo Dias. História do Amapá: O passado é o espelho do presente. Macapá: JM Editora Gráfica, 2009.

MOREIRA, A. F. B.; CANDAU, V. M. Educação escolar e cultura(s): construindo caminhos. Revista Brasileira de Educação, Rio de Janeiro, n. 23, p. 156-168, 2003. 
NEIRA, M. G. Educação física escolar: por uma pedagogia cultural. In: NEIRA, M. G.; NEIRA, M. G.; NUNES, M. L. F. Educação Física, currículo e cultura. São Paulo: Phorte Editora, 2009.

NUNES, M. L. F.; RÚBIO, K. O(S) Currículo(s) da Educação Física e a constituição da identidade de seus sujeitos. Currículo sem Fronteiras, v. 8, n. 2, p. 55-77, 2008.

PESSOA, Monica; VENERA, Raquel. Marabaixo: uma abordagem sobre a Educação e o patrimônio cultural afro-brasileiro. In: CONGRESSO INTERNACIONAL INTERDISCIPLINAR EM SOCIAIS E HUMANIDADES. 4., 2015, Foz do Iguaçu. Anais. Foz do Iguaçu: UNIOESTE, p. 1-17.

SILVA, T. T. Documentos de identidade: uma introdução às teorias curriculares. 3. ed. Belo Horizonte: Autêntica, 2011.

SOARES, C. L. et. al. Metodologia do ensino da Educação Física. São Paulo: Cortez, 1992.

TANI, G. et al. Educação Física escolar: São Paulo: Epu, 1988.

VIDEIRA, P. L. O Marabaixo do Amapá: encontro de saberes, histórias e memórias afroamapaenses. Revista Palmares: cultura afro-brasileira, Brasília, v. X, n. 8, p. 16-21, 2014.

Endereço para correspondência: brunacardosomcp@hotmail.com Bruna Cardoso Gonçalves Universidade Federal do Amapá Rod. Juscelino Kubitschek, km 02 Jardim Marco Zero 68903-419 - Macapá - AP, Brasil 